\title{
Attenuation of autophagy flux by 6-shogaol sensitizes human liver cancer cells to TRAIL-induced apoptosis via p53 and ROS
}

\author{
UDDIN MD. NAZIM and SANG-YOUEL PARK \\ Department of Biochemistry, College of Veterinary Medicine, Chonbuk National University, \\ Iksan, Jeonbuk 54596, Republic of Korea
}

Received April 11, 2018; Accepted November 20, 2018

DOI: $10.3892 /$ ijmm.2018.3994

\begin{abstract}
Tumor necrosis factor (TNF)-related apoptosis-inducing ligand (TRAIL) is a member of the TNF superfamily and is an antitumor drug that induces apoptosis in tumor cells with minimal or no effects on normal cells. Here, it is demonstrated that 6-shogaol (6-sho), a bioactive component of ginger, exerted anti-inflammatory and anticancer properties, attenuated tumor cell propagation and induced TRAIL-mediated cell death in liver cancer cells. The current study identified a potential pathway by revealing that TRAIL and 6-sho or chloroquine acted together to trigger reactive oxygen species (ROS) production, to upregulate tumor-suppressor protein 53 (p53) expression and to change the mitochondrial transmembrane potential (MTP). Treatment with $\mathrm{N}$-acetyl-L-cysteine reversed these effects, restoring the MTP and attenuated ROS production and p53 expression. Interestingly, treatment with 6-sho increased p62 and microtubule-associated proteins 1A/1B light chain 3B-II levels, indicating an inhibited autophagy flux. In conclusion, attenuation of 6-sho-induced autophagy flux sensitized cells to TRAIL-induced apoptosis via p53 and ROS, suggesting that the administration of TRAIL in combination with 6 -sho may be a suitable therapeutic method for the treatment of TRAIL-resistant Huh7 liver cells.
\end{abstract}

\section{Introduction}

Liver cancer is the third leading cause of cancer-associated mortality worldwide (1) and systemic chemotherapy is the main regimen for patients with late-stage liver cancer (2). Various chemotherapeutic regimens are currently administered as first-line therapy and drug resistance is a major clinical barrier to a successful treatment and modern chemotherapeutics,

Correspondence to: Dr Sang-Youel Park, Department of Biochemistry, College of Veterinary Medicine, Chonbuk National University, 79 Gobong-ro Road, Iksan, Jeonbuk 54596, Republic of Korea

E-mail: sypark@chonbuk.ac.kr

Key words: 6-shogaol, autophagy flux, tumor necrosis factor-related apoptosis-inducing ligand, tumor protein 53 , reactive oxygen species including combination chemotherapies, against liver cancer are still needed (3).

Tumor necrosis factor (TNF)-related apoptosis-inducing ligand (TRAIL) is a member of the TNF family that initiates apoptosis via interaction with death receptors (4). This interaction promotes death-inducing signaling complex formation and caspase- 8 activation, which in turn induce apoptosis (5). Interestingly, TRAIL is confirmed as a safe and efficient anticancer therapeutic agent that targets cancer cells (6). However, various cancer cells are resistant to TRAIL (7) and underlying pathways of TRAIL-resistance are associated with death receptors downregulation $(8,9)$ and upregulation of decoy receptors (10). Therefore, the use of TRAIL sensitizers is a mechanism towards overcoming TRAIL-resistance.

6-Shogaol (6-sho) is a bioactive component in ginger that has been widely used in traditional Chinese medicine $(11,12)$. Additionally, 6-sho has pharmacologic properties, including anti-inflammatory, anticancer and antioxidant activities $(13,14)$. Previous studies revealed that 6-sho initiates apoptosis in leukemia cells and liver, lung and colorectal cancer cells (15-19). Molecular pathways describing anticancer properties of 6-sho frequently include the activation of caspases.

Autophagy is a cellular catabolic degradation system that promotes the autophagosomal-lysosomal deterioration of cytosolic proteins and other cellular components (20). The first step in autophagy is the induction of vesicle nucleation, followed by the formation of autophagosome. The second step is a docking and fusion mechanism, in which the autophagolysosome is constructed by the fusion of the autophagosome and lysosomes and finally, the autophagolysosome is degraded into metabolic fuel by acid-containing enzymes (21). Under cellular stress, cell death can be induced by autophagy (22-24). In addition, autophagy inhibitors, including chloroquine (CQ), have been used in combination with various chemotherapeutic drugs and have been confirmed to sensitize tumor cells to apoptosis (25).

The tumor-suppressor protein 53 (p53) serves a vital role in the cellular response to DNA damage and in the protection of the genome from mutations (26). Previous studies have established a major role of $\mathrm{p} 53$ in the regulation of DNA repair, cell cycle arrest, apoptosis, senescence and autophagy (27-29). Several studies have revealed increased reactive oxygen species (ROS) production in cancer cells, which can be induced by various drugs (30) and increased ROS levels are responsible for cell death in various cancer cells (31). 
The current study aimed to elucidate the function of 6-sho as a sensitizing agent for TRAIL-induced apoptosis in Huh7 liver cancer cells. It was revealed that a combined regimen of 6-shol and TRAIL had a superior outcome compared with single treatment using 6 -sho or TRAIL.

\section{Materials and methods}

Cell culture. Human liver cancer cells (Huh7, Hep3B and HepG2) were obtained from the American Type Culture Collection (Manassas, VA, USA) and maintained in Dulbecco's modified Eagle's medium (Gibco; Thermo Fisher Scientific, Inc., Waltham, MA, USA) containing 10\% fetal bovine serum (FBS; Sigma-Aldrich; Merck KGaA, Darmstadt, Germany). Cells were cultured at $37^{\circ} \mathrm{C}$ with $5 \% \mathrm{CO}_{2}$ in humidified incubator.

Reagents. 6-sho was acquired from Cayman Chemical Company (Ann Arbor, MI, USA). TRAIL (200 ng/ml) was acquired from AbFrontier Co., Ltd. (Seoul, South Korea). CQ diphosphate and $N$-acetyl-L-cysteine (NAC) were purchased from Sigma-Aldrich (Merck KGaA). CQ was dissolved in water to give a $10 \mathrm{mM}$ stock solution and aqueous NAC $(10 \mathrm{mM})$ was prepared and added to cells $1 \mathrm{~h}$ at $37^{\circ} \mathrm{C}$ prior to treatment with TRAIL and 6-sho or CQ.

Cell viability assay. Huh7, HepG2 and Hep3B cells were seeded at $1.0 \times 10^{4}$ cells/well in 12 -well plates, pre-exposed to 6-sho $(20 \mu \mathrm{M})$ for $18 \mathrm{~h}$ at $37^{\circ} \mathrm{C}$ and were then treated with TRAIL $(200 \mathrm{ng} / \mathrm{ml})$ for $2 \mathrm{~h}$ at $37^{\circ} \mathrm{C}$. Cell morphology was assessed in Huh7 and Hep3B cells under an inverted microscope (magnification, x100) and cell viability was evaluated using crystal violet staining in Huh7 and HepG2 cells as previously described (32).

Trypan blue exclusion assay. Cell viability was evaluated by trypan blue exclusion assay (Sigma-Aldrich; Merck KGaA) using a hemocytometer in Huh7 and Hep3B cells. Following each treatment, cells were then trypsinized and re-suspended in PBS. Trypan blue dye solution $(0.4 \%)$ was added to the cell suspension for $5 \mathrm{~min}$ at room temperature. Unstained cells were viable and stained cells were dead. The total cell number and the number of trypan blue-positive cells were counted using a light microscope (magnification, x100) in a blinded manner. The percentage of surviving cells was calculated using the formula. Number of stained cells/number of total cells x100. Each experiments was performed in triplicate.

Immunofluorescent staining. Huh7 cells were cultured on poly-L-lysine coated coverslips (Sigma-Aldrich; Merck $\mathrm{KGaA}$ ). Following differentiation and treatments, cells were fixed with $4 \%$ paraformaldehyde for $15 \mathrm{~min}$ at room temperature and permeabilized with $0.1 \%$ Triton X-100 for $5 \mathrm{~min}$ at room temperature. Cells were then incubated for $60 \mathrm{~min}$ at room temperature with blocking solution (5\% FBS in Tris-buffered saline) followed by overnight incubation at $4^{\circ} \mathrm{C}$ with anti-p62 (1:250; cat. no. PA5-20839; Invitrogen; Thermo Fisher Scientific, Inc.) and anti-p53 (1:250; cat. no. 9286; Cell Signaling Technology, Inc., Danvers, MA, USA) antibodies. Following washing with PBS, cells were incubated with fluorescence-labeled secondary antibodies (Alexa Fluor ${ }^{\circledR}$ 488-conjugated donkey polyclonal anti-rabbit; 1:500; cat. no. A-21206; and Texas Red-X-conjugated goat polyclonal anti-mouse; 1:500; cat. no. T-6390; both Thermo Fisher Scientific, Inc.) for $2 \mathrm{~h}$ at room temperature in the dark. In addition, DAPI (1:1,000; cat. no. D9564; Sigma-Aldrich; Merck KGaA) was used to non-specifically stain the nuclei and samples were incubated with $50 \mu \mathrm{l}$ DAPI for $10 \mathrm{~min}$ at room temperature. Immunostaining was visualized under a fluorescence microscope (magnification, x400).

ROS determination. ROS formation was determined using the cell permeable fluorescent marker dihydroethidium (DHE). Briefly, following treatment, Huh7 cells (1.0x10 4 cells) were treated with $5 \mu \mathrm{M}$ DHE (Invitrogen; Thermo Fisher Scientific, Inc.) for $30 \mathrm{~min}$ at room temperature in the dark. Fluorescence was observed using a fluorescence plate reader at excitation and emission wavelengths of 518 and $605 \mathrm{~nm}$, respectively.

Transmission electron microscopy (TEM) analysis. Following fixation of Huh7 cells in 2\% glutaraldehyde (Electron Microscopy Sciences, Hatfield, PA, USA) and 2\% paraformaldehyde (EMS, USA) in $0.05 \mathrm{M}$ sodium cacodylate ( $\mathrm{pH} 7.2$; Electron Microscopy Sciences) for $2 \mathrm{~h}$ at $4^{\circ} \mathrm{C}$, specimens were fixed in $1 \%$ osmium tetroxide (Electron Microscopy Sciences) for $1 \mathrm{~h}$ at $4^{\circ} \mathrm{C}$, dehydrated with increasing ethanol $(25,50,70$, 90 and $100 \%$ ) for $5 \mathrm{~min}$ each at $4^{\circ} \mathrm{C}$ and embedded in epoxy resin (Embed 812; Electron Microscopy Sciences) for $48 \mathrm{~h}$ at $60^{\circ} \mathrm{C}$ according to the manufacturers' instructions. Ultrathin sections $(60 \mathrm{~nm})$ were prepared using an LKB-III ultratome (Leica Microsystems GmbH, Wetzlar, Germany) and were stained with $0.5 \%$ uranyl acetate (Electron Microscopy Sciences) for $20 \mathrm{~min}$ and $0.1 \%$ lead citrate (Electron Microscopy Sciences) for $7 \mathrm{~min}$ at room temperature. Images were recorded on a Hitachi $\mathrm{H} 7650$ electron microscope (magnification, x10,000; Hitachi, Ltd., Tokyo, Japan) installed at the Center for University-Wide Research Facilities (CURF) at Chonbuk National University.

Mitochondrial transmembrane potential (MTP) analysis. Changes in MTP were assessed using the cationic fluorescent marker, JC-1. Huh7 cells $\left(2.0 \times 10^{4}\right)$ were maintained on cover slips in a 24-well plate, incubated with $10 \mu \mathrm{M} \mathrm{JC}-1$ (Molecular Probes; Thermo Fisher Scientific, Inc.) at $37^{\circ} \mathrm{C}$ for $30 \mathrm{~min}$ and washed with PBS. Cells were mounted with DakoCytomation fluorescent mounting medium (cat. no. S3023; Dako; Agilent Technologies GmbH, Waldbronn, Germany) and analyzed at $485 \mathrm{~nm}$ for excitation and at $530 \mathrm{~nm}$ for emission using a fluorescence microscope (magnification, x400).

Western blot assay. Immunoblotting was performed as described previously (33). Briefly, radioimmunoprecipitation assay buffer (Qiagen, Inc., Valencia, CA, USA) was used to extract total proteins from Huh7 cells. The supernatant was collected by centrifugation $\left(13,282 \times \mathrm{g} ; 4^{\circ} \mathrm{C} ; 10 \mathrm{~min}\right)$. The protein concentration was determined using the Pierce BCA Protein Assay kit (Thermo Fisher Scientific, Inc.). Proteins $(30 \mu \mathrm{g})$ were separated on 10\% SDS-PAGE gels and blotted onto polyvinylidene fluoride membranes. Membranes were 
A 6-sho $(\mu \mathrm{M}) \quad-$

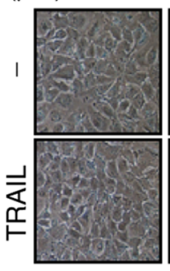

5

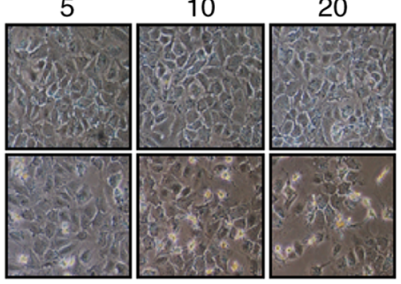

B

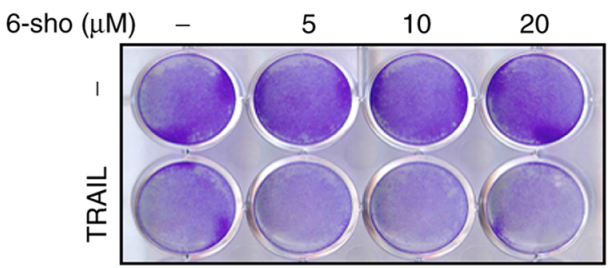

C
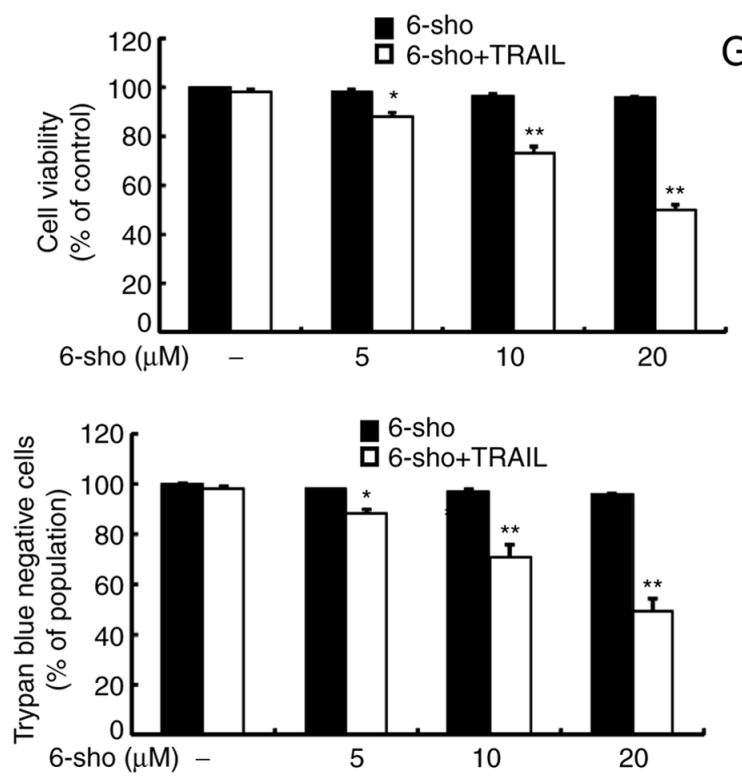

E 6-sho $(\mu \mathrm{M})$ 5
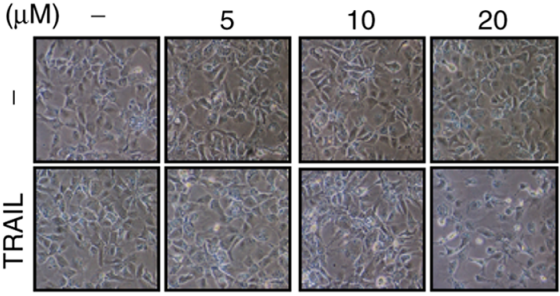

$\mathrm{F} \stackrel{0}{\bar{g}}$

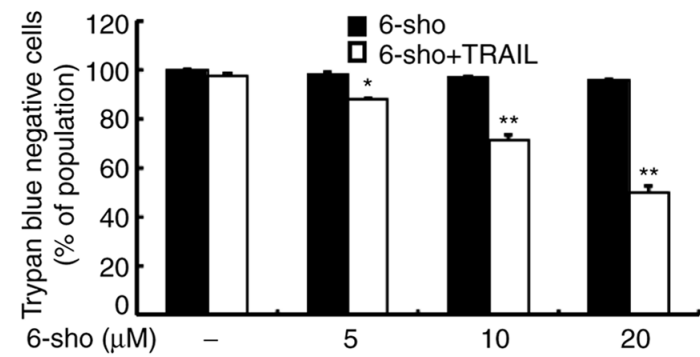

G

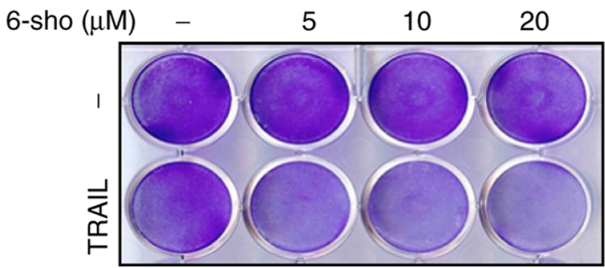

$\mathrm{H}$

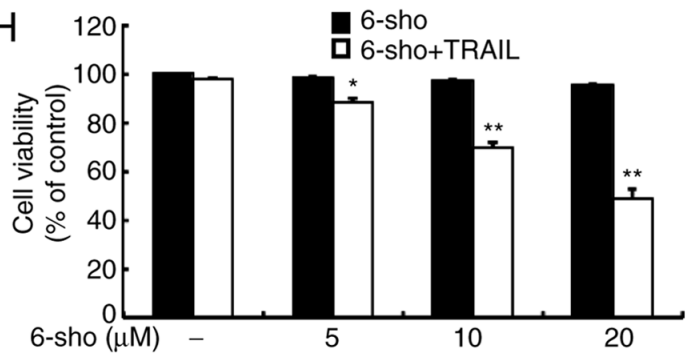

Figure 1. 6-Sho sensitizes liver cancer cells to TRAIL-induced apoptosis. Liver cancer cells were treated with 6-sho (5, 10 and $20 \mu \mathrm{M})$ for $18 \mathrm{~h}$ prior to exposure to TRAIL $(200 \mathrm{ng} / \mathrm{ml})$ for $2 \mathrm{~h}$. (A) Morphology of Huh7 cells evaluated by light microscopy (magnification, x100). (B) Huh7 viability assessed by crystal violet staining. (C) Mean density of crystal violet staining in Huh7. (D) Huh7 viability evaluated by trypan blue exclusion assays. (E) Morphology of Hep3B cells evaluated by light microscopy (magnification, x100). (F) Hep3B viability evaluated by trypan blue exclusion assays. (G) HepG2 viability assessed by crystal violet staining. (H) Mean density of crystal violet staining in HepG2. "P<0.01 and ${ }^{* *} \mathrm{P}<0.001$ vs. 6-sho. 6-Sho, 6-shogaol; TRAIL, tumor necrosis factor-related apoptosis-inducing ligand.

blocked with $5 \%$ non-fat dried milk at $25^{\circ} \mathrm{C}$ for $1 \mathrm{~h}$, followed by incubation with primary antibodies overnight at $4^{\circ} \mathrm{C}$. The $\beta$-actin antibody was from Sigma-Aldrich (cat. no. A2228; 1:2,000, Merck KGaA, Darmstadt, Germany), antibodies against microtubule-associated proteins $1 \mathrm{~A} / 1 \mathrm{~B}$ light chain $3 \mathrm{~B}$ (LC3)-I/II (cat. no. 3868; 1:1,000), cleaved caspase-3 (cas3; cat. no. $9661 ; 1: 500$ ) and p62 (cat. no. 5114; 1:1,000) were from Cell Signaling Technology, Inc., the p53 (cat. no. sc-6243; 1:1,000) antibody was from Santa Cruz Biotechnology, Inc. (Dallas, TX, USA) and the caspase-8 (cas8; cat. no. 551242; 1:1,000) antibody was from BD Biosciences (Franklin Lakes, NJ, USA). Membranes were incubated with horseradish peroxidase-conjugated secondary antibody (cat. no. 4410; 1:2,000; Cell Signaling Technology, Inc.) at $25^{\circ} \mathrm{C}$ for $1 \mathrm{~h}$. The immune-reactive protein bands were visualized using an enhanced chemiluminescence detection system (GE Healthcare Life Sciences, Chalfont, UK).
Statistical analysis. Statistical analyses were performed using GraphPad Prism (version 5.03; GraphPad Software, Inc., La Jolla, CA, USA). All experiments were performed in triplicate and data are presented as the mean \pm standard error. Significant differences between control and treated samples were analyzed using one-way analysis of variance followed by Duncan's post-hoc test or Student's t-test. $\mathrm{P}<0.05$ was considered to indicate a statistically significant difference.

\section{Results}

6-Sho sensitizes liver cancer cells to TRAIL-induced apoptosis. Changes in cell morphology were determined using a light microscope. Treatment with 6-sho or TRAIL alone only affected cell death minimally and no morphological changes were observed in TRAIL-treated cells compared to untreated cells (Fig. 1). However, combined treatment of TRAIL and 


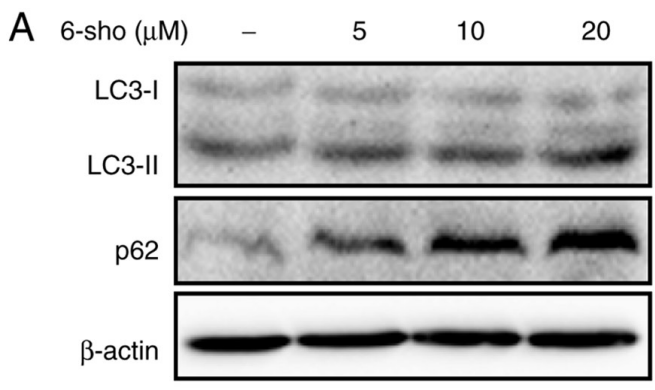

B 6-sho $(\mu \mathrm{M})$

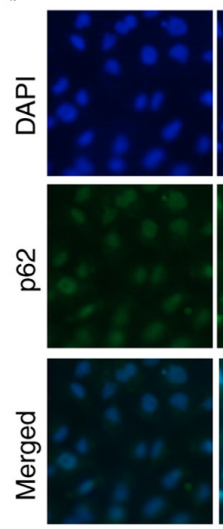

10

20

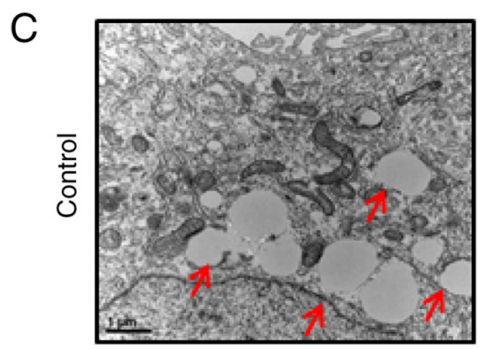

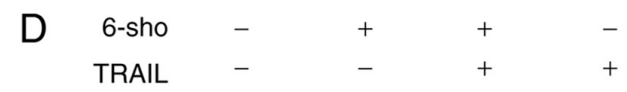
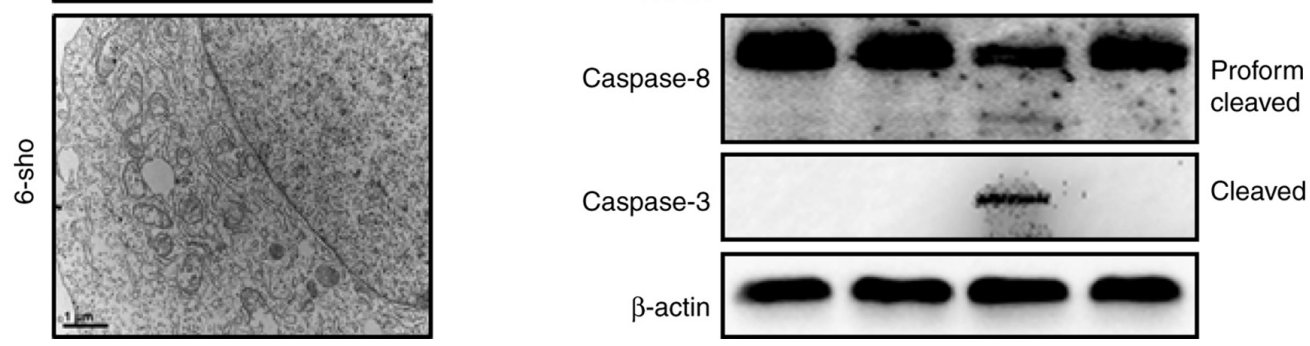

Figure 2. Autophagy flux is initiated by 6 -sho treatment in Huh7 cells. Huh7 cells were treated with 6 -sho $(5,10$ and $20 \mu \mathrm{M})$ for $18 \mathrm{~h}$ prior to exposure to TRAIL ( $200 \mathrm{ng} / \mathrm{ml}$ ) for $2 \mathrm{~h}$. (A) LC3-II and p62 levels assessed by western blotting using $\beta$-actin as control. (B) Huh7 cells stained with p62 antibody (green) and DAPI nuclear stain (blue) evaluated using fluorescence microscopy (magnification, $\mathrm{x} 400$ ). (C) TEM analysis to assess the formation of autophagosomes. (D) Cas 3 and cas 8 levels assessed by western blot assays using $\beta$-actin as control. 6-Sho, 6-shogaol; TRAIL, tumor necrosis factor-related apoptosis-inducing ligand; p62, tumor-suppressor protein 62; LC3, microtubule-associated proteins 1A/1B light chain 3B; cas, caspase.

A
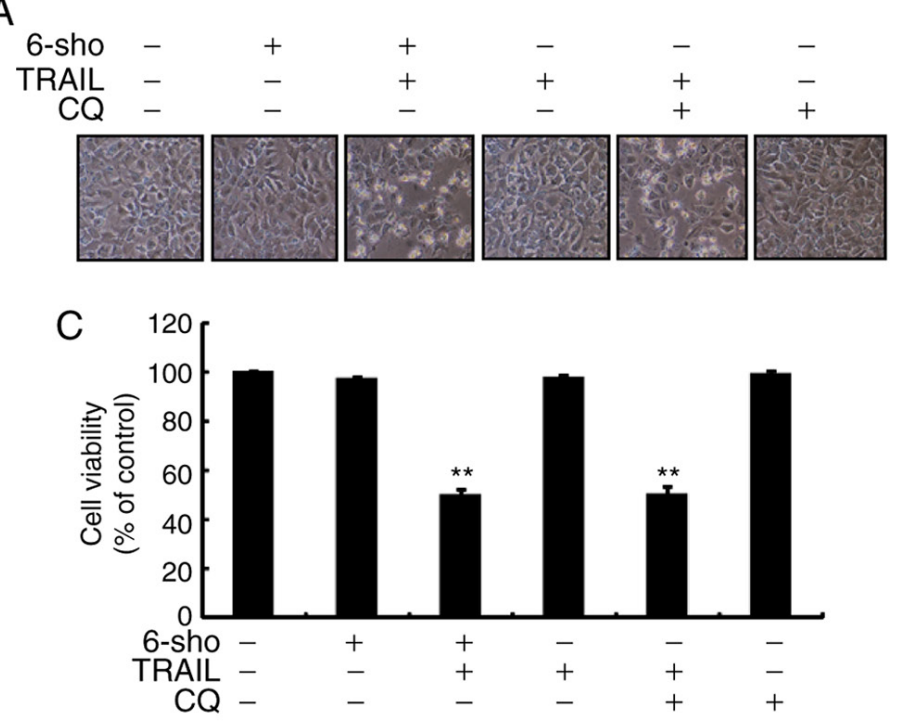

B

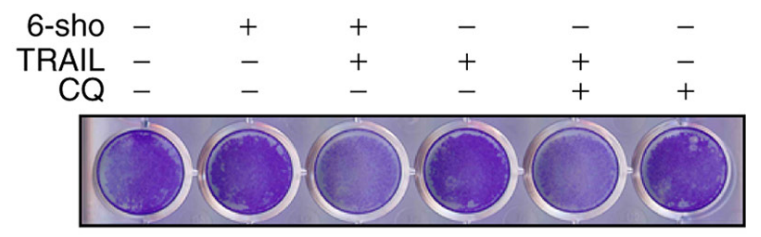

$\mathrm{D}$

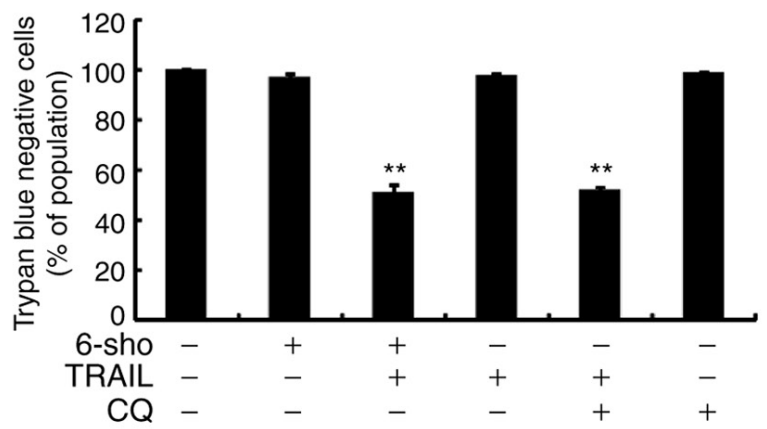

Figure 3. 6-Sho enhances TRAIL-initiated cell death by attenuating autophagy flux. Huh7 cells were pretreated with CQ (10 mM) for $1 \mathrm{~h}$ prior to exposure to 6-sho $(20 \mu \mathrm{M}$ ) for $18 \mathrm{~h}$ and TRAIL (200 ng/ml) for $2 \mathrm{~h}$. (A) Huh7 cell morphology evaluated by light microscopy (magnification, x100). (B) Cell viability assessed by crystal violet staining. (C) Mean density of crystal violet staining. (D) Cell viability evaluated by trypan blue exclusion assay. ${ }^{* *} \mathrm{P}<0.01 \mathrm{vs}$. TRAIL treatment group. 6-Sho, 6-shogaol; TRAIL, tumor necrosis factor-related apoptosis-inducing ligand; CQ, chloroquine.

6-sho at varying concentrations markedly increased cell death compared with 6-sho or TRAIL alone (Fig. 1). Cell morphology (Fig. 1A and E) and trypan blue exclusion assays (Fig. 1D and F) with Huh7 and Hep3B, and crystal violet 

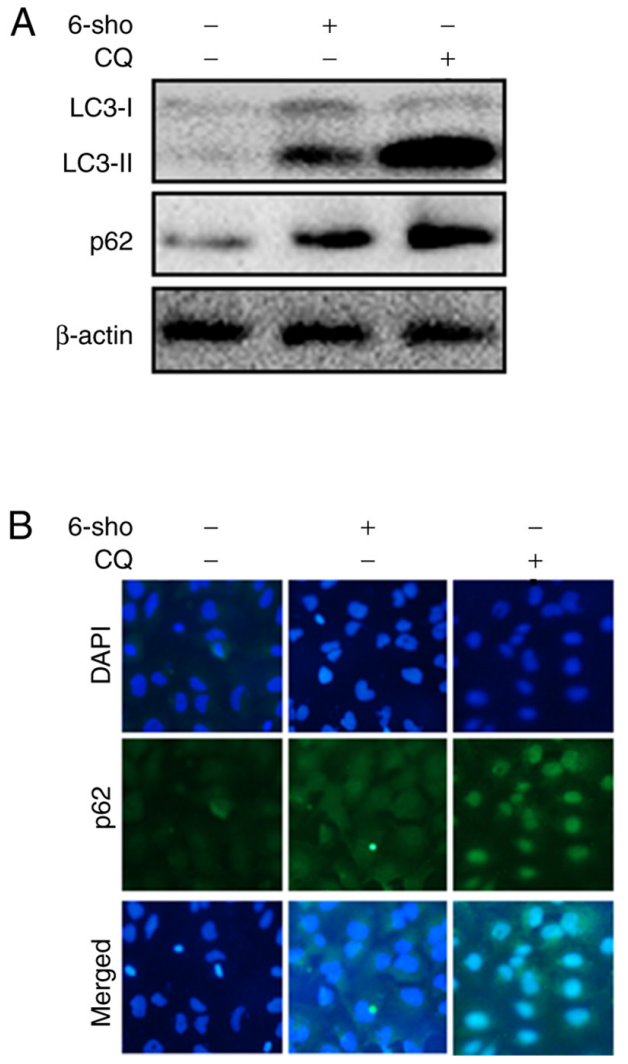

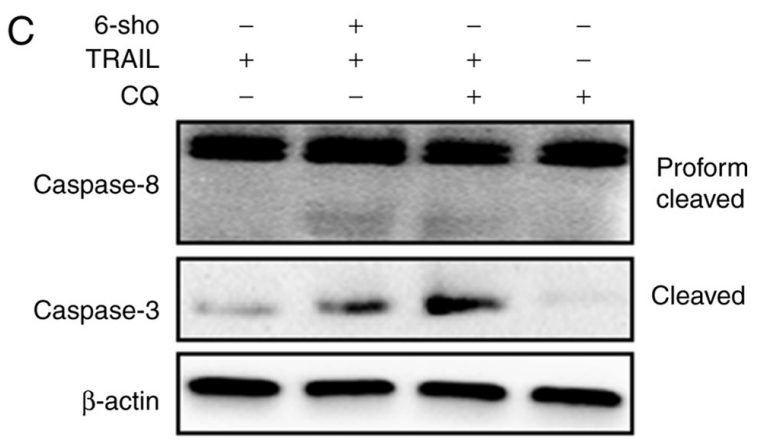

Figure 4. 6-Sho enhances the TRAIL-initiated apoptotic pathway by attenuating autophagy flux. Huh7 cells were pretreated with CQ (10 mM) for $1 \mathrm{~h}$ prior to exposure to 6 -sho $(20 \mu \mathrm{M})$ for $18 \mathrm{~h}$ and TRAIL $(200 \mathrm{ng} / \mathrm{ml})$ for $2 \mathrm{~h}$. (A) LC3-II and p62 levels assessed by western blotting using $\beta$-actin as control. (B) Cells stained with p62 antibody (green) and DAPI nuclear stain (blue) evaluated using fluorescence microscopy (magnification, $\mathrm{x} 400$ ). (C) Cas3 and cas8 levels assessed by western blot assays using $\beta$-actin as control. 6-Sho, 6-shogaol; TRAIL, tumor necrosis factor-related apoptosis-inducing ligand; CQ, chloroquine; p62, tumor-suppressor protein 62; LC3, microtubule-associated proteins 1A/1B light chain 3B; cas, caspase.

assays (Fig. 1B and G) and mean density of crystal violet assay data (Fig. 1C and H) for Huh7 and Hep-G2 suggested that combined treatment with TRAIL and 6-sho upregulated cell death compared with the single treatments. The data indicated that 6 -sho pretreatment sensitized liver cancer cells to TRAIL-induced apoptosis.

Autophagy flux is induced by 6-sho in Huh7 cells. LC3-II and p62 expressions increased following 6-sho treatments in a dose-dependent manner (Fig. 2A). Immunofluorescent staining further demonstrated that 6-sho increased p62 levels dependent on the dose (Fig. 2B). TEM analysis revealed increased autophagy and empty vacuoles in the untreated control compared with 6-sho-treated cells (Fig. 2C). Combined treatment with TRAIL and 6-sho increased the cleaved cas8 and cleaved cas 3 levels compared with the untreated or single treatments (Fig. 2D).

6-Sho enhances TRAIL-induced cell death by attenuating autophagy flux. Cell morphology indicated increased cell death through treatment with TRAIL and 6-sho $(20 \mu \mathrm{M})$ or CQ $(20 \mu \mathrm{M})$ (Fig. 3A). Combined treatment regimen using CQ and TRAIL markedly increased cell death (Fig. 3B) and significantly decreased cell viability compared with the untreated and the single treatment groups (Fig. 3C and D). The findings suggested that 6 -sho sensitized cells to TRAIL-induced cell death by attenuating autophagy flux.
6-Sho enhances the TRAIL-induced apoptotic pathway by attenuating autophagy flux. LC3-II and p62 expression levels were markedly increased in Huh7 cells treated with 6-sho or CQ compared with untreated cells. This confirmed that 6-sho inhibited autophagy flux and observed effects were enhanced with CQ treatment (Fig. 4A). Immunofluorescent staining demonstrated enhanced p62 protein levels in the 6-sho and CQ treated cells compared to the untreated cells (Fig. 4B). Combined treatment regimen with TRAIL and CQ or 6-sho increased cleaved cas 3 and cleaved cas 8 protein levels (Fig. 4C).

6-Sho enhances TRAIL-mediated p53 expression. 6-Sho treatment increased p53 expression in Huh7 cells in a dose-dependent manner (Fig. 5A); immunofluorescent staining further confirmed these findings (Fig. 5B). p53 levels were increased in cells treated with TRAIL combined with 6-sho or CQ compared with the TRAIL or CQ single treatment (Fig. 5C). The increase in p53 expression was attenuated when the cells were preincubated with $N$-acetyl-L-cysteine (NAC) for $1 \mathrm{~h}$ prior to treatment with TRAIL and 6-sho or CQ (Fig. 5D).

Attenuation of autophagy stimulates ROS production and changes in the MTP. In Fig. 6A, it was demonstrated that ROS levels were significantly increased in Huh7 cells treated with TRAIL combined with 6-sho or CQ compared to the TRAIL single treatment $(\mathrm{P}<0.01)$ and this increase was reversed in cells pretreated with NAC prior to TRAIL and 6-sho or CQ 


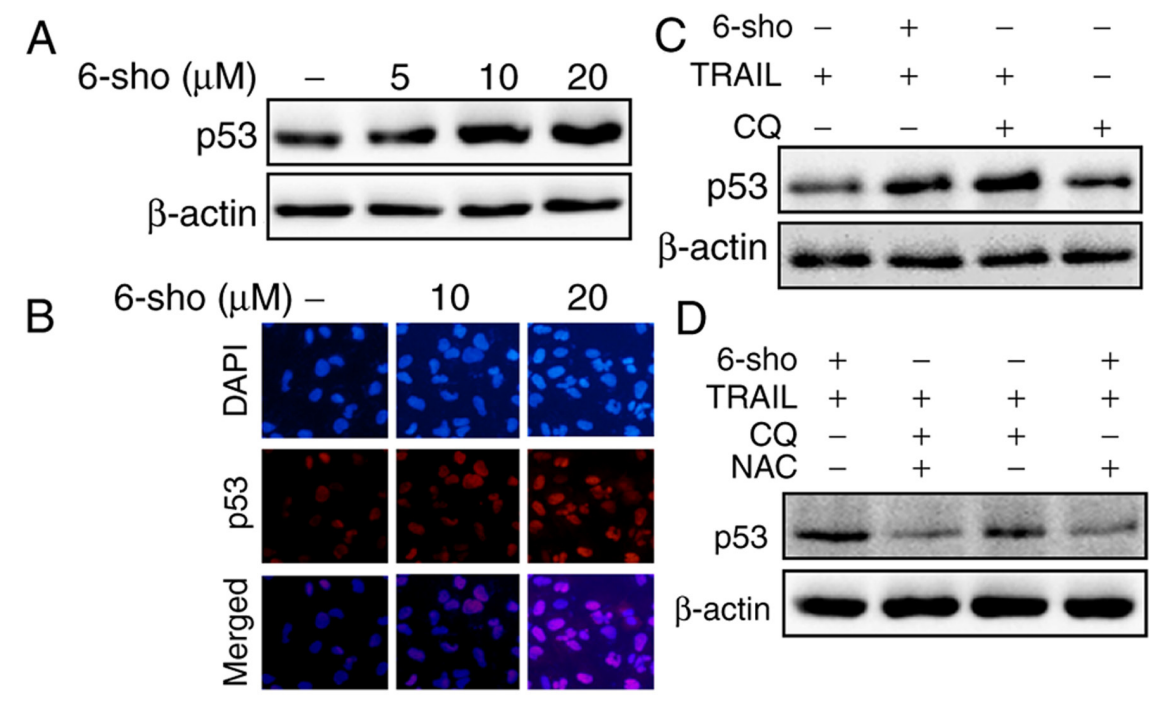

Figure 5. 6-Sho enhances TRAIL-mediated p53 expression. Huh7 cells were treated with 6-sho (5, 10 and $20 \mu \mathrm{M})$ for 18 h. (A) p53 levels assessed by western blot analysis using $\beta$-actin as control. (B) Cells stained with p53 antibody (red) and DAPI nuclear stain (blue) evaluated using fluorescence microscopy (magnification, x400). Western blot analysis of p53 levels in Huh7 cells were pretreated with (C) CQ (10 mM) for $1 \mathrm{~h}$ or (D) NAC (10 mM) for $1 \mathrm{~h}$ followed by CQ $(10 \mathrm{mM})$ for $1 \mathrm{~h}$ prior to exposure to 6-sho $(20 \mu \mathrm{M})$ for $18 \mathrm{~h}$ and TRAIL $(200 \mathrm{ng} / \mathrm{ml})$ for $2 \mathrm{~h}$. 6-Sho, 6-shogaol; TRAIL, tumor necrosis factor-related apoptosis-inducing ligand; CQ, chloroquine; p53, tumor-suppressor protein 53; NAC, $N$-acetyl-L-cysteine.

treatment. Green fluorescence, as observed in cells treated with TRAIL combined with 6-sho or CQ, indicated lower MTP values and pretreatment with NAC restored MTP values (Fig. 6B). Yellow-orange fluorescence indicated correct potential of the intracellular mitochondrial membrane $(80-100 \mathrm{mV})$ from the polarized mitochondria. The findings suggested that 6-sho-induced autophagy flux attenuation enhanced TRAIL-induced apoptosis via ROS production and MTP reduction.

\section{Discussion}

TRAIL is a member of the TNF superfamily, first discovered in the 1990s $(34,35)$ and is regarded as a selective antitumor drug inducing apoptosis in tumor cells with minimal effects on healthy cells (36). TRAIL has gained increasing attention due to its therapeutic role as a tumor cell-specific apoptosis inducer (37). 6-Sho has multiple anticancer effects, including attenuation of proliferation and invasion, and initiation of cell death (38). Autophagy is a highly conserved catabolic pathway exhibiting decreased levels of proteins and organelles that enhance survival and it occurs in physiological and pathological situations (39). Activation of several autophagy-associated genes, including LC3, phosphatidylinositol-4,5-bisphosphate 3-kinase, p62 and beclin (40-42), induces autophagosome formation. p53 induces cell death by promoting apoptosis moderators (43). ROS is associated with cell death, and promotes apoptosis and autophagy through various signaling mechanisms (44-46).

Studies have demonstrated that liver cancer cells are resistant to TRAIL-induced apoptosis $(47,48)$. In the present study, Huh7 cells were used in all experiments, while HepG2 and Hep3B we cells were used in cell viability assay. This study was demonstrated that a combined regimen of 6-sho and TRAIL caused a marked induction of cell death in liver cancer cells compared with the single treatments. The main focus of the current study was on autophagy and caspase signaling,
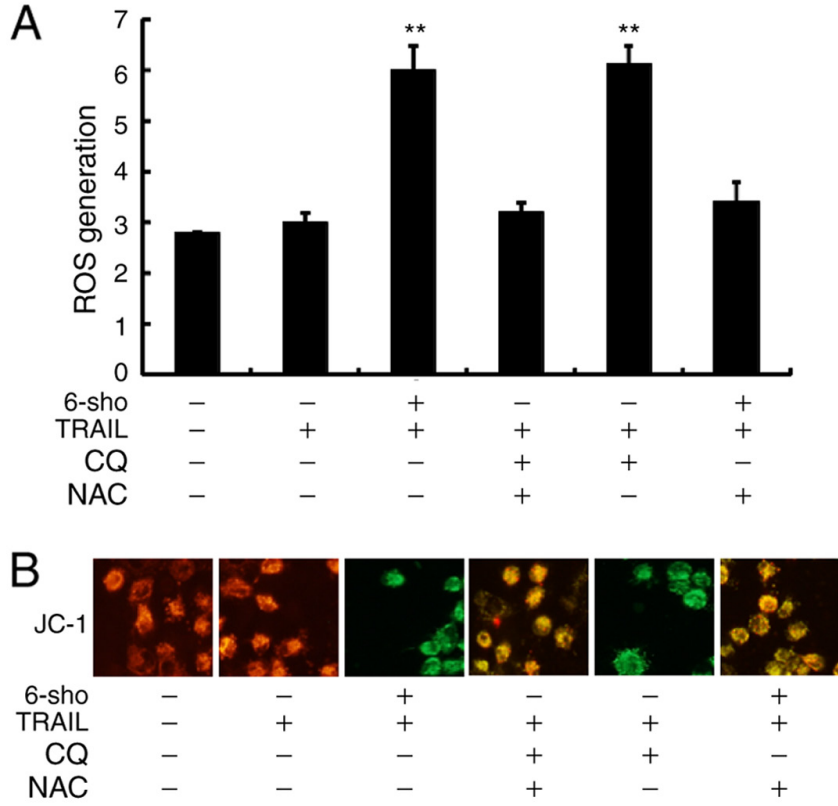

Figure 6. Attenuation of autophagy stimulates ROS generation and changes in mitochondrial transmembrane potential. Huh7 cells were pretreated with NAC $(10 \mathrm{mM})$ for $1 \mathrm{~h}$ followed by CQ $(10 \mathrm{mM})$ for $1 \mathrm{~h}$ prior to exposure to 6 -sho $(20 \mu \mathrm{M})$ for $18 \mathrm{~h}$ and TRAIL $(200 \mathrm{ng} / \mathrm{ml})$ for $2 \mathrm{~h}$. (A) ROS levels assessed by spectrofluorometer. (B) Fluorescence microscopy analysis of JC-1 aggregates (red), monomers (green) and correct potential (yellow-orange; magnification, $\mathrm{x} 400){ }^{* *} \mathrm{P}<0.01$ vs. TRAIL treatment group. 6-Sho, 6-shogaol; TRAIL, tumor necrosis factor-related apoptosis-inducing ligand; CQ, chloroquine; NAC, $N$-acetyl-L-cysteine; ROS, reactive oxygen species.

including caspase-8 and caspase-3. Combined treatment of 6-sho and TRAIL upregulated cleaved cas 3 and cleaved cas8 compared with single treatments mediating autophagy. Further caspases, including caspase-9, may serve pivotal roles in 6-sho-mediated TRAIL activity and further investigations are required regarding mitochondrial pathways, including cytochrome c, MTP and the activation of caspase-9. 
Previously, 6-sho was reported to initiate cell cycle arrest and autophagy in A549 cells (49). The present findings confirmed that LC3-II and p62 expression increased following 6-sho treatments. It was further observed that a combined regimen of TRAIL and 6-sho or CQ attenuated cell viability and increased cell death compared with single treatment regiments. Previously, it has been reported that p53 is a mediator for CQ-induced apoptotic initiation in cancer cells (50). The present findings confirmed that TRAIL combined with 6-sho or CQ increased p53 expression compared with single treatment groups. Previous evidence revealed that CQ augments dysfunctional mitochondria and ROS production in prostate cancer cells (51). The present findings suggested that treatment of 6-sho enhanced TRAIL-mediated apoptosis via ROS production and MTP reduction.

In conclusion, treatment with 6-sho and TRAIL induced apoptosis via p53 and ROS, suggesting that the administration of TRAIL in combination with 6-sho is a suitable therapeutic treatment of TRAIL-resistant Huh7 liver cells.

\section{Acknowledgments}

Not applicable.

\section{Funding}

The present study was supported by the National Research Foundation of Korea (grant no. 2016R1A2B2009293).

\section{Availability of data and materials}

The datasets used and/or analyzed during the current study are available from the corresponding author on reasonable request.

\section{Authors' contributions}

UMDN and S-YP designed the study. UMDN performed the experiments. UMDN and S-YP analyzed the data and prepared the manuscript. All authors reviewed the results and approved the final version of the manuscript.

\section{Ethics approval and consent to participate}

Not applicable.

\section{Patient consent for publication}

Not applicable.

\section{Competing interests}

The authors declare that they have no competing interests.

\section{References}

1. Dhanasekaran R, Limaye A and Cabrera R: Hepatocellular carcinoma: Current trends in worldwide epidemiology, risk factors, diagnosis, and therapeutics. Hepat Med 4: 19-37, 2012.

2. Chi HC, Chen SL, Cheng YH, Lin TK, Tsai CY, Tsai MM, Lin YH, Huang YH and Lin KH: Chemotherapy resistance and metastasis-promoting effects of thyroid hormone in hepatocarcinoma cells are mediated by suppression of FoxO1 and Bim pathway. Cell Death Dis 7: e2324, 2016.
3. Wei F, Jiang X, Gao HY and Gao SH: Liquiritin induces apoptosis and autophagy in cisplatin (DDP)-resistant gastric cancer cells in vitro and xenograft nude mice in vivo. Int J Oncol 51: 1383-1394, 2017.

4. Helmy SA, El-Mesery M, El-Karef A, Eissa LA and El Gayar AM: Chloroquine upregulates TRAIL/TRAILR2 expression and potentiates doxorubicin anti-tumor activity in thioacetamide-induced hepatocellular carcinoma model. Chem Biol Interact 279: 84-94, 2018.

5. Falschlehner $\mathrm{C}$, Emmerich $\mathrm{CH}$, Gerlach $\mathrm{B}$ and Walczak $\mathrm{H}$ : TRAIL signalling: Decisions between life and death. Int $\mathrm{J}$ Biochem Cell Biol 39: 1462-1475, 2007.

6. Trivedi R and Mishra DP: Trailing TRAIL resistance: Novel targets for TRAIL sensitization in cancer cells. Front Oncol 5: $69,2015$.

7. Zhang L and Fang B: Mechanisms of resistance to TRAIL-induced apoptosis in cancer. Cancer Gene Ther 12: 228-237, 2005.

8. Zhang Y and Zhang B: TRAIL resistance of breast cancer cells is associated with constitutive endocytosis of death receptors 4 and 5. Mol Cancer Res 6: 1861-1871, 2008.

9. Ozoren N, Fisher MJ, Kim K, Liu CX, Genin A, Shifman Y, Dicker DT, Spinner NB, Lisitsyn NA and El-Deiry WS: Homozygous deletion of the death receptor DR4 gene in a nasopharyngeal cancer cell line is associated with TRAIL resistance. Int J Oncol 16: 917-925, 2000.

10. Sanlioglu AD, Dirice E, Aydin C, Erin N, Koksoy S and Sanlioglu S: Surface TRAIL decoy receptor-4 expression is correlated with TRAIL resistance in MCF7 breast cancer cells. BMC Cancer 5: 54, 2005.

11. Ali BH, Blunden G, Tanira MO and Nemmar A: Some phytochemical, pharmacological and toxicological properties of ginger (Zingiber officinale Roscoe): A review of recent research. Food Chem Toxicol 46: 409-420, 2008.

12. Haniadka R, Rajeev AG, Palatty PL, Arora R and Baliga MS: Zingiber officinale (ginger) as an anti-emetic in cancer chemotherapy: A review. J Altern Complement Med 18: 440-444, 2012.

13. Li F, Nitteranon V, Tang X, Liang J, Zhang G, Parkin KL and $\mathrm{Hu} \mathrm{Q}$ : In vitro antioxidant and anti-inflammatory activities of 1-dehydro-[6]-gingerdione, 6-shogaol, 6-dehydroshogaol and hexahydrocurcumin. Food Chem 135: 332-337, 2012.

14. Dugasani S, Pichika MR, Nadarajah VD, Balijepalli MK, Tandra S and Korlakunta JN: Comparative antioxidant and anti-inflammatory effects of [6]-gingerol, [8]-gingerol, [10]-gingerol and [6]-shogaol. J Ethnopharmacol 127: 515-520, 2010.

15. Chen CY, Liu TZ, Liu YW, Tseng WC, Liu RH, Lu FJ, Lin YS, Kuo SH and Chen CH: 6-shogaol (alkanone from ginger) induces apoptotic cell death of human hepatoma p53 mutant Mahlavu subline via an oxidative stress-mediated caspase-dependent mechanism. J Agric Food Chem 55: 948-954, 2007.

16. Hu R, Zhou P, Peng YB, Xu X, Ma J, Liu Q, Zhang L, Wen XD, Qi LW, Gao N and Li P: 6-Shogaol induces apoptosis in human hepatocellular carcinoma cells and exhibits anti-tumor activity in vivo through endoplasmic reticulum stress. PLoS One 7: e39664, 2012.

17. Pan MH, Hsieh MC, Kuo JM, Lai CS, Wu H, Sang S and Ho CT: 6-Shogaol induces apoptosis in human colorectal carcinoma cells via ROS production, caspase activation, and GADD 153 expression. Mol Nutr Food Res 52: 527-537, 2008.

18. Liu Q, Peng YB, Zhou P, Qi LW, Zhang M, Gao N, Liu EH and Li P: 6-Shogaol induces apoptosis in human leukemia cells through a process involving caspase-mediated cleavage of eIF2 $\alpha$. Mol Cancer 12: 135, 2013.

19. Kim MO, Lee MH, Oi N, Kim SH, Bae KB, Huang Z, Kim DJ, Reddy K, Lee SY, Park SJ, et al: [6]-shogaol inhibits growth and induces apoptosis of non-small cell lung cancer cells by directly regulating Akt1/2. Carcinogenesis 35: 683-691, 2014.

20. Levine B and Klionsky DJ: Development by self-digestion: Molecular mechanisms and biological functions of autophagy. Dev Cell 6: 463-477, 2004.

21. Mizushima N: Autophagy: Process and function. Genes Dev 21: 2861-2873, 2007

22. Bergmann A: Autophagy and cell death: No longer at odds. Cell 131: 1032-1034, 2007.

23. Maiuri MC, Zalckvar E, Kimchi A and Kroemer G: Self-eating and self-killing: Crosstalk between autophagy and apoptosis. Nat Rev Mol Cell Biol 8: 741-752, 2007.

24. Codogno P, Mehrpour M and Proikas-Cezanne T: Canonical and non-canonical autophagy: Variations on a common theme of self-eating? Nat Rev Mol Cell Biol 13: 7-12, 2011. 
25. Kimura T, Takabatake Y, Takahashi A and Isaka Y: Chloroquine in cancer therapy: A double-edged sword of autophagy. Cancer Res 73: 3-7, 2013.

26. Chiu HW, Su YC and Hong JR: Betanodavirus B2 protein triggers apoptosis and necroptosis in lung cancer cells that suppresses autophagy. Oncotarget 8: 94129-94141, 2017.

27. Kruse JP and Gu W: Modes of p53 regulation. Cell 137: 609-622, 2009.

28. Toledo F and Wahl GM: Regulating the p53 pathway: In vitro hypotheses, in vivo veritas. Nat Rev Cancer 6: 909-923, 2006.

29. Di J, Huang H, Qu D, Tang J, Cao W, Lu Z, Cheng Q, Yang J, Bai J, Zhang Y and Zheng J: Rap2B promotes proliferation, migration, and invasion of human breast cancer through calcium-related ERK1/2 signaling pathway. Sci Rep 5: 12363, 2015.

30. Zhao J, Zhang L, Li J, Wu T, Wang M, Xu G, Zhang F, Liu L, Yang $J$ and Sun S: A novel pyrazolone-based derivative induces apoptosis in human esophageal cells via reactive oxygen species (ROS) generation and caspase-dependent mitochondria-mediated pathway. Chem Biol Interact 231: 1-9, 2015.

31. Menzies FM, Fleming A and Rubinsztein DC: Compromised autophagy and neurodegenerative diseases. Nat Rev Neurosci 16 : 345-357, 2015

32. Nazim UM, Moon JH, Lee JH, Lee YJ, Seol JW, Eo SK, Lee JH and Park SY: Activation of autophagy flux by metformin downregulates cellular FLICE-like inhibitory protein and enhances TRAIL- induced apoptosis. Oncotarget 7: 23468-23481, 2016.

33. Nazim UM, Moon JH, Lee YJ, Seol JW and Park SY: PPAR $\gamma$ activation by troglitazone enhances human lung cancer cells to TRAIL-induced apoptosis via autophagy flux. Oncotarget 8: 26819-26831, 2017.

34. Ashkenazi A, Pai RC, Fong S, Leung S, Lawrence DA, Marsters SA, Blackie C, Chang L, McMurtrey AE, Hebert A, et al: Safety and antitumor activity of recombinant soluble Apo2 ligand. J Clin Invest 104: 155-162, 1999.

35. Wang S and El-Deiry WS: TRAIL and apoptosis induction by TNF-family death receptors. Oncogene 22: 8628-8633, 2003.

36. Falschlehner C, Ganten TM, Koschny R, Schaefer U and Walczak H: TRAIL and other TRAIL receptor agonists as novel cancer therapeutics. Adv Exp Med Biol 647: 195-206, 2009.

37. Green KL, Brown C, Roeder GE, Southgate TD and Gaston K: A cancer cell-specific inducer of apoptosis. Hum Gene Ther 18: 547-561, 2007

38. Han MA, Woo SM, Min KJ, Kim S, Park JW, Kim DE, Kim SH, Choi YH and Kwon TK: 6-Shogaol enhances renal carcinoma Caki cells to TRAIL-induced apoptosis through reactive oxygen species-mediated cytochrome $\mathrm{c}$ release and down-regulation of c-FLIP(L) expression. Chem Biol Interact 228: 69-78, 2015.

39. Ferraro E and Cecconi F: Autophagic and apoptotic response to stress signals in mammalian cells. Arch Biochem Biophys 462 210-219, 2007

40. Xie Z and Klionsky DJ: Autophagosome formation: Core machinery and adaptations. Nat Cell Biol 9: 1102-1109, 2007.
41. Ohsumi Y and Mizushima N: Two ubiquitin-like conjugation systems essential for autophagy. Semin Cell Dev Biol 15: 231-236, 2004

42. Jia L, Macey MG, Yin Y, Newland AC and Kelsey SM: Subcellular distribution and redistribution of Bcl-2 family proteins in human leukemia cells undergoing apoptosis. Blood 93: 2353-2359, 1999.

43. Chen L, Xiong YQ, Xu J, Wang JP, Meng ZL and Hong YQ: Juglanin inhibits lung cancer by regulation of apoptosis, ROS and autophagy induction. Oncotarget 8: 93878-93898, 2017.

44. Park SY and Kim Y: Surfactin inhibits immunostimulatory function of macrophages through blocking NK-kappaB, MAPK and Akt pathway. Int Immunopharmacol 9: 886-893, 2009.

45. Yang TC, Lai CC, Shiu SL, Chuang PH, Tzou BC, Lin YY, Tsai FJ and Lin CW: Japanese encephalitis virus down-regulates thioredoxin and induces ROS-mediated ASK1-ERK/p38 MAPK activation in human promonocyte cells. Microbes Infect 12: 643-651, 2010

46. Son Y, Cheong YK, Kim NH, Chung HT, Kang DG and Pae HO: Mitogen-activated protein kinases and reactive oxygen species: How can ROS activate MAPK pathways? J Signal Transduct 2011: 792639, 2011

47. Yamanaka T, Shiraki K, Sugimoto K, Ito T, Fujikawa K, Ito M, Takase K, Moriyama M, Nakano T and Suzuki A: Chemotherapeutic agents augment TRAIL-induced apoptosis in human hepatocellular carcinoma cell lines. Hepatology 32: 482-490, 2000.

48. Shankar S and Srivastava RK: Enhancement of therapeutic potential of TRAIL by cancer chemotherapy and irradiation: Mechanisms and clinical implications. Drug Resist Updat 7 : 139-156, 2004.

49. Hung JY, Hsu YL, Li CT, Ko YC, Ni WC, Huang MS and Kuo PL: 6-Shogaol, an active constituent of dietary ginger, induces autophagy by inhibiting the AKT/mTOR pathway in human non-small cell lung cancer A549 cells. J Agric Food Chem 57: 9809-9816, 2009.

50. Amaravadi RK, Yu D, Lum JJ, Bui T, Christophorou MA, Evan GI, Thomas-Tikhonenko A and Thompson CB: Autophagy inhibition enhances therapy-induced apoptosis in a Myc-induced model of lymphoma. J Clin Invest 117: 326-336, 2007.

51. Saleem A, Dvorzhinski D, Santanam U, Mathew R, Bray K, Stein M, White E and DiPaola RS: Effect of dual inhibition of apoptosis and autophagy in prostate cancer. Prostate 72: 1374-1381, 2012.

(i) $\Theta$ This work is licensed under a Creative Commons Attribution-NonCommercial-NoDerivatives 4.0 International (CC BY-NC-ND 4.0) License. 